\title{
Institutional Logics Shaping E-health Projects: A Case Study of the EMR System in Dubai
}

\section{Noora Alghatam}

Corresponding Author: Noora Alghatam nhalghatam@uob.edu.bh

Received: 18 September 2018 Accepted: 10 October 2018 Published: 15 October 2018

Publishing services provided by Knowledge $\mathrm{E}$

(c) Noora Alghatam. This article is distributed under the terms of the Creative Commons

Attribution License, which permits unrestricted use and redistribution provided that the original author and source are credited.

Selection and Peer-review under the responsibility of the Sustainability and Resilience Conference Committee.

\section{G OPEN ACCESS}

\section{Abstract}

This is a research-in-progress article that aims to explore the extent emergent formats for public health sector as new projects for EMR systems are launched and negotiated locally. The article adopts institutional theory and the concept of institutional logics to explore ICTs projects in Dubai's public health organizations. To set the scene for this study, the article traces temporal developments and trends of health ICT projects, through an institutional analysis of associated discourses, over the course of almost a decade.

The article identifies three institutional influences during consecutive periods of time that shaped how ICT projects are depicted and approached. The aim is to explore how these new formats for health projects are enacted by healthcare workers and their implications for public health organizations.

\section{Introduction}

National across the world are actively engaged in the development of health information systems and particularly electronic health records (EHR), which are considered a means to modernize and resolve inefficiencies in the health sector domain. These large-scale and integrated systems are relatively new even in the context of countries that were pioneers in the adoption of these technologies such as the US and the UK and their experience of the National Program for IT (NPfIT). Similarly, countries in the Middle East and particularly the GCC nations, which are the focus of this study, are in the early years of implementation for EHR. And it is up to the healthcare professionals to enact these systems and attain these benefits.

With such high hopes on transforming the public healthcare systems, some academics argue that the focus should be directed to perceptions and experiences of the healthcare professionals who are at the heart of these large-scale projects. For instance, explore how healthcare professionals act as institutional agents who can 
either promote and embed new managerial practices or defend aspects of clinical professionalism at work. In Lockett et. al's (2014) study, health care staff are conceptualized as institutional entrepreneurs who are part of the NHS collaboratives (health institutions and universities) and play a role in translating or enacting policies and research (evidence-based studies) into the practice as ICTs are introduced. These actors were found to enact different type of work that is undertaken by these actors that include envisaging change; engaging in change; embedding and reflecting on past decisions to learn from them. These actors were significant in reshaping institutional practices to sustain the translation of evidence- based innovations into clinical practice. In another study, Jensen et. al (2009) present a case study of introducing electronic prescribing into public health institutions in Denmark as part of a government initiative to reform and modernize the health sector. The physicians found that the data entry process was time-consuming. In addition to this, the physicians' authority was challenged by the new system. Thus, they questioned the work responsibilities at times and refused to accept the logic inscribed in the system. The physicians created workarounds since elements of the system did not make sense.

In what ways are institutions shaping public e-health projects in the GCC?

\section{Institutional Theory}

Institutional theory focuses on the role of institutions, which according to Scott (2001) represent durable structures that influence actions of people in organizations and society.

Institutional ideas arrive into various contexts through institutional carriers (Avgerou 2002), which may take the form of human actors or even technological artifacts. Thornton and Ocasio (1999) define institutional logic as socially constructed patterns of practices and values and rules, which are reproduced by agents. The concept is used to emphasize the multiplicity of logics at the same time organizations (Greenwood et. al 2010).

The concept of institutional logics is often employed to show contradictory elements of institutions that can at times be aligned or conflict. The paper examines the Amazon monitoring system for around 4 decades using primary and secondary data to show the different dominating institutional logics over periods of time and how this is reflected in the design of the systems.

The concept has been employed in various studies of health information systems such as the implementation of the NHS project (Currie and Spyridonidis 2016), the 
conflicts of institutional logics and their resolution in the Nigerian healthcare context (Asangansi 2012); institutional logics and changes to pharmacist's professional work (Goodrick and Reay 2011).

The concept has been employed in studies of GIS system implementation and ICT projects in healthcare. Sahay et. al (2010) employed the concept to explore challenges in setting up a decentralized HMIS system in the context of Tajikistan. The findings suggest that the conflicting institutional logics were irreconcilable and challenged the implementation of such a system in a decentralized and flexible approach.

\section{Case study}

For more than a decade, the development of an integrated electronic medical record (EMR) system in Dubai's healthcare sector has been a significant objective of the state and the Health Authority. As such, the aim is to go beyond existing legacy systems and associated practices to build a center of excellence in healthcare (http://www. govhealthit.com). This has been a central theme in the discourse on administrative reform and modernization of healthcare in the emirate as presented in conferences, policy documents, media coverage and publications.

Following the successful implementation of e-government systems in Dubai for nearly a decade, there has been an interest in improving e-services in the health sector. In 2005, there have been early efforts to transform the existing systems and set up databases for all paper medical records and to train staff to use them (Khaleej Times, AMEinfo 2005). This coincided with the establishment of the Dubai Health Authority (DHA) in 2006, which took over the role of the Ministry of Health. In the following year, the health sector also officially launched HIRAS (healthcare information reporting and analysis system), which collects medical information and codes it based on international standards. HIRAS was locally developed and used in Dubai's healthcare city, which includes many of the state's private healthcare institutions. All these efforts led to an important milestone of the public healthcare project in January 2008, where the clinical information systems were upgraded to EMR systems.

A number of significant developments occurred in 2012 and 2013. One important milestone was conducting an evaluative study of electronic medical records in 2012, by using the electronic medical record adoption model (EMRAM) survey. This was one of the first surveys of its kind in the Middle East region. The findings suggest that $70 \%$ of health information systems are still in the early stages and need some time to reach the stage of robust clinical intelligence and clinical information exchange. In 
2013 a taskforce was established which consisted of members from public and private healthcare institutions to oversee plans and policies, and their role is expected to become bigger and more significant as the initiative progresses over time. One of the significant developments includes the set up of the Smart Healthcare Model, which was unveiled in October 2013.

\section{Methodology}

The methodology for this research-in-progress paper is based on a combination of coding methods and discourse analysis to explore various policy documents, newspaper articles and WebPages that include objectives presented in ministry of health websites in Dubai.

The first stage of the analysis included examining online newspaper articles and journal papers to build a narrative on how the EMR systems were set up and developed for the period of 2004-2016. This narrative was later classified into three main periods: health ICT prior to we-based services, health ICT in parallel to e-government, health ICT during economic restructuring.

The second stage of analysis drew on some ideas from grounded theory and discourse analysis. The process involved creating two tables to analyze the main statements from policy documents and official health IT webpage from Dubai's health authority. For Dubai this included the UAE's 2021 vision, Dubai ERM model, current health mission and vision, and standardization documents. The statements were selected based on three categorizations: managerial/technical, economic and professional/scientific, institutional logics.

The coding process became more detailed for each of the theoretical categories. The managerial logic included ideas such as: internal collaboration, integration, standardization, convenience and efficiency. The economic logic included ideas such as: cost saving, private sector collaboration. The professional scientific logic included concepts such as evidence-based medicine and healthcare professional values and needs. As analysis progressed, the process of coding an additional category emerged which is context-specific issues for healthcare in each case and cultural aspects. This was especially relevant to challenges in implementation of e-health systems.

The third stage involved a series of narrative construction. First, one was developed based on the three time periods related to ICT use. Second a narrative was constructed between based on the three institutional logics: scientific, managerial and economic- 
restructuring logics. Finally, a narrative was constructed which identifies alignment and conflict between institutional logics was constructed.

The research will also include a pilot study and interviews with a number of managers in the department of health and healthcare professionals in hospitals. The aim is to explore what elements of the various ideas are enacted in their daily activities and how this contributes to the formation of a socio-technical assemblage for EMR systems in the public health sector.

\section{Analysis}

\subsection{The web-based technologies period and the managerial logic}

A decade of e-government projects in the UAE that were underpinned by notions of new public management and particularly customer-orientation. The speed in developments and internationally acclaimed outcomes shaped some initiatives in healthcare and the expectations of the public. The managerial logic consisted of two strands. First, the standardization of ICT development through the formalization of institutional structures such as section Dubai's health authority for e-health and Dubai's e-government central organization in the early zooos. Second, the logic involved a change in conceptualizing ICTs, which moved from being tools for internal administration to citizen facing systems that supported service delivery and access to information. This was evident in 2004 as e- health services were promoted. Third, the managerial logic also consisted of a drive for innovation in healthcare as smart applications were introduced to assist patients in obtaining services and information. These systems, which included smart beds for patients, collected data that supported the decisions of healthcare staff. Such innovations generated large amounts of data and are currently considered a means of big data analytics. The arrival of the managerial logic came to support existing scientific logics for EMR development, which continued to dominate practices and expected outcomes from ICT use.

\subsection{EMR developments and the economic-restructuring logic}

Discourses on healthcare in the GCC were increasingly focusing on the economic sustainability of the existing healthcare model and exploring new options for the future.

This introduced a hybrid economic and restructuring logic in public healthcare. This hybrid logic consisted of three elements. First, ICTs were enablers of public sector 
policies such as the national healthcare insurance initiative that required data to be shared between public healthcare organizations and insurance companies. Second, the new systems were to be employed to support significant organizational restructuring as public and private collaboration initiatives for healthcare insurance were taking place. Third, the ICTs were supporting a new vision for healthcare which shifted from an organizational focus to the notion of a wider health ecosystem. This networked view of healthcare was aligned with the notion of smart cities and smart living as noted in the Dubai 2021 national agenda. The changes in the healthcare sector was also accompanied by a resurfacing of EBM ideas and the use of EMR systems. For instance, there was the set up of the EMR committee in 2015. Thus, the regulative measures came to support the institutionalization of the EMR systems and the scientific logic more than replace them with economic-restructuring logics.

\section{Discussion and Conclusion}

\subsection{The EMR system as both an institutional carrier and institutional enactment}

Studies of ICTs in the public sector often emphasize that institutional logics are multiple and vary across time depending on the social context. The changing institutional logics illustrated in this study supports Rajao and Hayes's (2011) work on how different logics exist and shape the way GIS systems are introduced and used. One of the contributions of this study is the argument that the EMR system are not only responding to shifts in institutional dynamics but also acts a carrier of institutional logics over time. As noted earlier the EMR system carried with it managerial, scientific and economic institutional logics during the period from the 1998 to 2016.

Studies of ICTs as institutional carriers often focus on the transmission of new ideas and values in a particular context as a single event. In contrast, I argue that institutional carrier can be conceptualized from a processual view as an artefact which can have different ideas and values inscribed over time. This is illustrated in the longitudinal study of healthcare in Dubai as the same EMR system came to be a carrier multiple times with numerous logics.

The introduction of institutional logics was enabled by the enhancement in functions and features of the EMR system which was inscribed with scientific and collaborative values and practices. As noted in Dunleavy et. al's (2006) work, ICTs in public sector organizations, and within the sector of public health, reflect the concept of digital 
era governance as they are moving towards centralization after decades of NPM and decentralization. This trend is evident in our study as the EMR system which shifted from databases in individual healthcare institutions towards standardization of practices and terms that formed the foundation for citizen-facing services that are part of the e-health and e-government period. Later, the EMR systems were introduced to support a wider network approach that integrates the public and private sector to enact the national health insurance laws. The case illustrates that the dual role of the EMR system as both a carrier of multiple institutional logics and a technology enactment (Fountain 2001) in itself. For instance, events and policies related to Dubai's e-health and e-government initiatives and economic changes all contributed in legitimizing the adoption and use of the EMR systems.

\subsection{The EMR system's enactment and future use}

Institutional studies of IS in healthcare often focus on how institutions overlap and are negotiated by various actors involved. This theme is illustrated in Miscione's (2007) study of tele-health in the Upper Amazon region as the ICTs were shaped by an institutional alliances between scientific and sociocultural institutions. Our study supports work on institutional alliances as the EMR was introduced and legitimized by the alliance between e-government and medical professionalism that promotes the use of EMR systems to serve e-health initiatives for patient empowerment and convenience. Later, the institutional alliance between managerial institution and medical professionalism shifted the use of ICTs for organizational purposes towards a networked ecosystems for healthcare to integrate public and private sector healthcare institutions. This is particularly the case as healthcare systems in general are extended with smart applications such as the "Sehaty" program, and the potential to employ big data analytics to support decisions across public and private sectors.

Studies of IS in healthcare often discuss the persistence of professional and scientific institutions. This has been evident in this study as the scientific institutional logic was present throughout the three main periods for ICT use. The question that is raised here is related to prospective use of the EMR system and the extent in which it is shaped by the scientific institutional logic or if other logics will dominate the enactments of healthcare professionals. This supports Faraj and Azad (2009) argument that egovernment projects consist of multiple enactments by different actors which may shift towards one groups' values over the others. The regulative aspects of healthcare supports a move towards being customer-oriented in service delivery and moving 
towards an ecosystem view and approach to ICT use in health. However, prospective use by healthcare professionals will determine the organizational and institutional outcomes of the EMR systems. As noted in studies of e-government and public value (Cordella and Bonina 2010), it is the middle managers or in this case the healthcare staff who interact with people and enact ICT policies that negotiate an overarching public value for systems. One area for future research is to explore the dynamics between the scientific, professional and socio-cultural institutions that are played out by healthcare professionals' practices as they incorporate EMR systems in daily activities.

\section{References}

[1] Asangansi I, Braa K. The emergence of mobile-supported national health information systems in developing countries. Studies in Health Technology and Informatics Journal. 2010;160(1):540.

[2] Avgerou, C. (2002). The Institutional Nature of I.C.T. and Organizational Change. In Information Systems and Global Diversity C. (Avgerou, C. Ed.), p. 23, Oxford University Press. New York.

[3] Azad, B. \& Faraj, S., 2009. E-Government institutionalizing practices of a land registration mapping system. Government Information Quarterly, 26(1), pp.5-14.

[4] Cordella, A., \& Bonina, C. M. (2012). A public value perspective for ICT enabled public sector reforms: A theoretical reflection. Government Information Quarterly, 29(4), 512-520. Journal of Public Administration Research and Theory, 16(3), pp.467- 494.

[5] Currie, G., \& Spyridonidis, D. (2016). Interpretation of multiple institutional logics on the ground: Actors' position, their agency and situational constraints in professionalised contexts. Organization Studies, 37, 77-98.

[6] Fountain, J., 2001. Building the Virtual State: Information Technology and Institutional Change, Washington, DC: Brookings Institution Press.

[7] Goodrick, E. and T. Reay. 2011. 'Constellations of Institutional Logics: Changes in the Professional Work of Pharmacists', Work and Occupations, 38, 3, 372-416.

[8] Greenwood, R., Diaz, A. M., Li, S. X., \& Lorente, ]. C. 2010. The multiplicity of institutional logics and the hetero? geneity of organizational responses. Organization Science, 21: 521-539.

[9] Jensen, T.B., Kj\aergaard, A. \& Svejvig, P., 2009. Using institutional theory with sensemaking theory: a case study of information system implementation in healthcare. Journal of Information Technology, 24(4), pp.343-353. 
[10] Lockett A, El Enany N, Currie G, et al. A formative evaluation of Collaboration for Leadership in Applied Health Research and Care (CLAHRC): institutional entrepreneurship for service innovation. Health Serv Deliv Res 2014; 2: 31.

[11] McGivern, G., G. Currie, E. Ferlie, L. Fitzgerald, and J. Waring 2015. "'Hybrid managerprofessionals" identity work, the maintenance and hybridization of professionalism in managerial contexts', Public Administration

[12] Miscione, G., 2007. Telemedicine in the Upper Amazon: Interplay with local health care practices. MIS quarterly, 31(2), pp.403-425.

[13] Rajão, R., and N. Hayes. 2009. Conceptions of control and IT artefacts: an institutional account of the Amazon rainforest monitoring system. Journal of Information Technology 24:320-331.

[14] Sahay, S., Sæbbø, J.I., Mekonnen, S.M. and Gizaw, A.A. (2010), "Interplay of institutional logics and implications for deinstitutionalization: Case study of HMIS implementation in Tajikistan", Information Technologies \& International Development, Vol. 6 No. 3, pp. 19-32.

[15] Scott, W.R., 2001. Institutions and Organizations, Sage Publications.

[16] Thornton, P. H., \& Ocasio, W. 1999. Institutional logics and the historical contingency of power in organizations: Executive succession in the higher education publish? ing industry, 1958-1990, I. American Journal of Sociology, 105: 801-843. 